Alle. $1+3000$

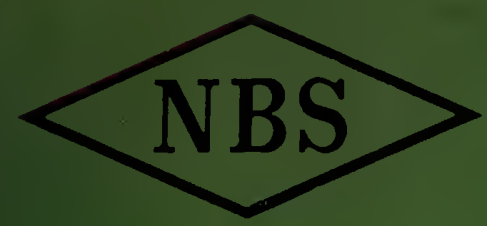

Eechnical Note

no. 333

\title{
THE VISCOSITY AND THERMAL CONDUCTIVITY COEFFICIENTS OF DILUTE ARGON BETWEEN 100 AND $2000^{\circ} K$
}

H. J. M. HANLEY

U. S. DEPARTMENT OF COMMERCE NATIONAL BUREAU OF STANDARDS 


\section{THE NATIONAL BUREAU OF STANDARDS}

The National Bureau of Standards is a principal focal point in the Federal Government for assuring maximum application of the physical and engineering sciences to the advancement of technology in industry and commerce. Its responsibilities include development and maintenance of the national standards of measurement, and the provisions of means for making measurements consistent with those standards; determination of physical constants and properties of materials; development of methods for testing materials, mechanisms, and structures, and making such tests as may be necessary, particularly for government agencies; cooperation in the establishment of standard practices for incorporation in codes and specifications; advisory service to government agencies on scientific and technical problems; invention and development of devices to serve special needs of the Government; assistance to industry, business, and consumers in the development and acceptance of commercial standards and simplified trade practice recommendations; administration of programs in cooperation with United States business groups and standards organizations for the development of international standards of practice; and maintenance of a clearinghouse for the collection and dissemination of scientific, technical, and engineering information. The scope of the Bureau's activities is suggested in the following listing of its four Institutes and their organizational units.

Institute for Basic Standards. Electricity. Metrology. Heat. Radiation Physics. Mechanics. Applied Mathematics. Atomic Physics. Physical Chemistry. Laboratory Astrophysics. ${ }^{*}$ Radio Standards Laboratory: Radio Standards Physics; Radio Standards Engineering.* * Office of Standard Reference Data.

Institute for Materials Research. Analytical Chemistry. Polymers. Metallurgy. Inorganic Materials. Reactor Radiations. Cryogenics. ${ }^{* *}$ Office of Standard Reference Materials.

Central Radio Propagation Laboratory. ** Ionosphere Research and Propagation. Troposphere and Space Telecommunications. Radio Systems. Upper Atmosphere and Space Physics.

Institute for Applied Technology. Textiles and Apparel Technology Center. Building Research. Industrial Equipment. Information Technology. Performance Test Development. Instrumentation. Transport Systems. Office of Technical Services. Office of Weights and Measures. Office of Engineering Standards. Office of Industrial Services.

* NBS Group, Joint Institute for Laboratory Astrophysics at the University of Colorado.

* Located at Boulder, Colorado. 


\title{
NATIONAL BUREAU OF STANDARDS Eechnical Note 333
}

ISSUED March 11, 1966

\section{THE VISCOSITY AND THERMAL CONDUCTIVITY COEFFICIENTS OF DILUTE ARGON BETWEEN 100 AND $2000^{\circ} \mathrm{K}$}

\author{
H. J. M. Hanley \\ Cryogenics Division \\ Institute for Materials Research \\ National Bureau of Standards \\ Boulder, Colorado
}

NBS Technical Notes are designed to supplement the Bureau's regular publications program. They provide a means for making available scientific data that are of transient or limited interest. Technical Notes may be listed or referred to in the open literature.

For sale by the Superintendent of Documents, U.S. Government Printing Office 
Abstract

1. Introduction --

2. The Potential Functions

3. Kinetic Theory Expressions for the Transport Coefficients

4. Method of Calculation and Results

4.1 The Lennard-Jones Potential -

4.2 The Exp: 6 Potential -

4.3 The Kihara Potential -

5. Thermal Conductivity - 10

6. Self-Diffusion -

7. Conclusion - 10

8. Acknowledgement - 10

9. Appendix I - 13

10. Appendix II - 16

11. Appendix III - 19

12. References - 22 

THE VISCOSITY AND THERMAL CONDUCTIVITY COEFFICIENTS OF DILUTE ARGON

BETWEEN 100 AND $2000^{\circ} \mathrm{K}$ FROM THE KIHARA POTENTIAL FUNCTION

H. J. M. Hanley

The variation of the force constants of the Lennard-Jones, Exp: 6, and Kihara potential functions was investigated by comparing the Chapman-Enskog kinetic theory expression for the viscosity coefficient with the experimental viscosity of dilute argon. It was found that this variation was more pronounced than expected. It was necessary to rationalize the choice of the force constants of each function before using the function to compare theory with experimental data. Of the three, the Kihara was found to give the best correlation, and tables of the viscosity and thermal conductivity coefficients of dilute argon between 100 and $2000^{\circ} \mathrm{K}$ were computed from this potential and the Chapman-Enskog equations.

Key Words: Force-constants, Potential functions, Lennard-Jones, Kihara, Exp: 6, Viscosity, Argon, Correlation, Thermal conductivity, Self-diffusion, Kinetic theory

\section{INTRODUCTION}

In this note the Chapman-Enskog kinetic theory expressions for the viscosity, thermal conductivity, and self-diffusion coefficients were correlated with experimental data and tables of the two former properties are presented.

Argon was chosen because it is the simplest molecule to treat theoretically and because of the relatively large amount of experimental data available. Although, of course, there are numerous discussions on this topic, and there are several tables of argon transport properties in the literature [1-5]*, a really satisfactory treatment of even dilute argon has not been achieved. This is not unexpected in view of the difficulties of examining any realistic model in a non-equilibrium system. For instance, not only are there many claims that a particular potential function is to be recommended, but there is also wide disagreement over the recommended values for the force-constants or parameters for a given function, such as the Lennard-Jones, (Table I).

TABLE I

$\begin{array}{rrr}\epsilon / \mathrm{k},{ }^{\circ} \mathrm{K} & \sigma, \AA & \operatorname{Ref} . \\ 93.3 & 3.542 & 2 \\ 119.1 & 3.491 & 3 \\ 119.5 & 3.421 & 4 \\ 128.0 & 3.398 & 6 \\ 152 & 3.305 & 7\end{array}$

Table I. Parameters for the Lennard-Jones function, (Eq. I) selected by various workers.

In view of this rather unsatisfactory situation it was felt that still another examination of the data was justified. This has turned out to be fruitful in that the potential function was found to vary in a manner not fully discussed previously $[6,8]$. It will also be shown that the correlation between theory and experimental data is much more affected by the choice of the force-constants than previously reported. It is hoped that the method given will be suitable for other gases of relatively simple structure.

* Numbers in brackets refer to references. 
The selection of a function and a choice of "best values" for the corresponding force-constants was based on an examination of the viscosity coefficient alone. Experimental thermal conductivity and self-diffusion coefficients are not as extensive nor as reliable as desired, and it is well known that potential parameters obtained from sources such as the equation of state, often lead to discrepancies when applied to transport phenomena (this point will be briefly commented on in Appendix III).

\section{THE POTENTIAL FUNCTIONS}

The discussion was restricted to the three most commonly used functions, the Lennard-Jones, the Exp: 6, and the Kihara. The Kihara, in particular, has received much attention in the literature recently $[3,9,10]$. As the functions are well known and have been fully discussed [1, 11, 12], it is only necessary to outline them here. If $U(r)$ is the interaction potential of two molecules separated by distance $r$, and $\epsilon$ is the maximum energy of attraction, or energy minimum, the potentials are written;

Lennard-Jones

$$
U(r)=4 \epsilon\left[(\sigma / r)^{12}-(\sigma / r)^{6}\right],
$$

where $\sigma$ is the value of $r$ at $U(r)=0$.

Exp: 6

$$
U(r)=\frac{\epsilon}{1-6 / \alpha}\left[\frac{\sigma}{\alpha} e^{\alpha\left(1-r / r_{m}\right)}-\left(r_{m} / r\right)^{6}\right],
$$

where $r_{m}$ is the value of $r$ at the energy minimum and $\alpha$ a parameter which represents the steepness of the repulsive part of the function.

\section{$\underline{\text { Kihara }}$}

$$
\begin{gathered}
U(r)=4 \epsilon\left[\left(\frac{\sigma-a}{r-a}\right)^{12}-\left(\frac{\sigma-a}{r-a}\right)^{6}\right], r>a \\
U(r)=\infty, \quad r \leq a .
\end{gathered}
$$

Here the finite size of the molecule is taken into consideration by including a core diameter, a. (For the Lennard-Jones, $a=0$. )

\section{KINETIC THEORY EXPRESSIONS FOR THE TRANSPORT COEFFICIENTS}

The kinetic theory for a dilute gas (see Appendix II) is formally complete [1], the ChapmanEnskog treatment of the Boltzmann equation giving the transport coefficients in terms of collision integrals which are functions of the gas dynamics and thus, of the intermolecular potential. It is the lack of knowledge of the latter which restricts the applicability of the kinetic theory expressions. The expressions used for the calculations are;

Viscosity $(\eta)$

$$
\eta 10^{7}=\frac{266.93(\mathrm{MT})^{1 / 2}}{\mathrm{R}^{2} \Omega^{(2,2)^{*}}\left(\mathrm{~T}^{*}\right)} f_{\eta} g \mathrm{~cm}^{-1} \mathrm{sec}^{-1},
$$


Thermal Conductivity

$$
\begin{array}{rlrl}
\lambda I 0^{7} & =\frac{1989 \cdot 1 \quad(\mathrm{~T} / \mathrm{M})^{1 / 2}}{R^{2} \Omega^{(2,2) *}\left(\mathrm{~T}^{*}\right)} \mathrm{f}_{\eta} \operatorname{cal} \mathrm{cm}^{-1} \mathrm{sec}^{-1} \mathrm{deg}^{-1} \\
& \equiv \frac{15}{4} \frac{R}{\mathrm{M}} \eta 10^{7} & \text { cal } \mathrm{cm}^{-1} \mathrm{sec}^{-1} \mathrm{deg}^{-1},
\end{array}
$$

\section{Self Diffusion (D)}

$$
D=\frac{0.002628\left(T^{3} / M\right)^{1 / 2}}{P R^{2} \Omega^{(1,1) *}\left(T^{*}\right)} \quad f_{D} \mathrm{~cm}^{2} \mathrm{sec}^{-1}
$$

where: $M=$ molecular weight. ( $M=39.948$ for argon)

$R=$ a distance parameter i.e., $R \equiv \sigma$ for the Lennard-Jones and Kihara, and $R \equiv r_{m}$ for the Exp: 6 .

$T=$ the absolute temperature, ${ }^{\circ} \mathrm{K}$

$R=$ the gas constant per mole

$\Omega^{(2,2) *}\left(T^{*}\right)$ and $\Omega^{(1,1) *}\left(T^{*}\right)=$ the reduced collision integrals (reduced by dividing by the integrals for the rigid sphere case) at the reduced temperature $T^{*}$, where $T^{*}=T /(\epsilon / k)$ with $k$ the Boltzmann constant.

$f_{\eta}, f_{\lambda}$, and $f_{D}$ are terms accounting for higher mathematical approximations to $\eta$, $\lambda$, and $D$ and are slowly varying functions of $\mathrm{T}^{*}$ which seldom differ from unity by more than about $0.5 \%$. To be consistent with the accuracy of the experimental viscosity data at extreme temperatures, they can be omitted from Eqs. 4, 5, and 6 without significant error.

Tables of the collision integrals as a function of $T^{*}$ for each of the potentials can be obtained from several sources (e.g., Refs. 1, 3), the numerical values of the integrals depend on the method of integration but it was verified that the choice of any particular set of tables made no significant difference to the results presented here. The tables used were, in fact, taken from Refs. 1,3 , and 11.

Note that Eq. 5 for the thermal conductivity is only applicable to monatomic gases. For polyatomic gases a separate correction is necessary for any intermal degree of freedom. The coefficient of selfdiffusion is an artificial quantity but is included as a further check on the potential and the force constants chosen.

\section{METHOD OF CALCULATION AND RESULTS*}

It was first necessary to determine the "best values" for the parameters for each of the functions. As has been stated, the preliminary calculations require the experimental viscosity coefficients only. The general method is now outlined.

For all functions, the first step was to substitute experimental values of $\eta$, corresponding temperatures $T$, and a sensible value for $R$ into Eq. 4, hence obtaining $\Omega(2.2) *$ (T) as a function of T. An interpolation routine next generated $T^{*}$ by interpolating for these $\Omega(2,2)^{*}\left(T^{*}\right)$ values in the given set of $\Omega(2,2)^{*}\left(T^{*}\right)$ and $T^{*}$ for the function in question. As $\epsilon / \mathrm{k}=T / T^{*}$, $\epsilon / \mathrm{k}$ was then found as a function of $T$ for a particular $R$. Incidently, these $\epsilon / k$ versus $T$ curves were very sensitive to a change in the experimental viscosity coefficient and gave clear indications as to which sets of experimental data were internally consistent. (The viscosity coefficients at one atmosphere

* Much of this section is taken from the account in Ref. 13. The material is included for completeness. 
were taken from Refs. 14-21; the same experimental data were used for all three potentials.) The procedure was repeated with several values of $R$, varying $R$ by about $6 \%$ overall. It was found that the shape of the $\epsilon / \mathrm{k}$ versus $T^{*}$ curves indicated the best value of $R$. After selection of $R$ and $\epsilon / \mathrm{k}$ the potentials were compared by examining the deviation curves between theory and experiment.

The details are as follows:

\subsection{LENNNARD-JONES}

The $\varepsilon / k$ versus $T$ curves for the $\sigma$ 's of Table I obtained by following the above procedure are shown in Fig. 1. The theoretical collision integrals were taken from the tables in Ref. 3 . The "best value" for $\sigma$ was taken to be that associated with the curve with the least variation of $\varepsilon / \mathrm{k}$ over the widest temperature range allowing for the experimental scatter and interpolation error (about $1 \%$ ). Trial and error selected $\sigma=3.41 \AA$. A corresponding best value of $\epsilon / \mathrm{k}$ was about $125^{\circ} \mathrm{K}$ from Fig. $I$ and this was adjusted to $\epsilon / \mathrm{k}=124.9^{\circ} \mathrm{K}$ to obtain agreement between the experimental and calculated viscosity coefficients at $293^{\circ} \mathrm{K}$. $293^{\circ} \mathrm{K}$ was chosen because the experimental viscosity coefficient at this temperature has been carefully measured by many workers [e.g., Refs. 16, 18, 20] with agreement of about $0.2 \%$. Using the selected $\sigma$ and $\varepsilon / \mathrm{k}$, (Table II), a percentage deviation curve over the temperature range 90 to $1200^{\circ} \mathrm{K}$ was plotted, Fig. 2. It is to be noted in this figure that agreement between theory and experiment is substantially better than obtained by previous correlations $[2-4]$.

\section{TABLE II}

$\begin{array}{cll}\text { Function } & \epsilon / \mathrm{k},{ }^{\circ} \mathrm{K} & \mathrm{R}, \AA \\ \mathrm{I}-\mathrm{J} & 124.9 & 3.41 \\ \text { Exp: } 6 & 122.9 & 3.86 \\ \text { Kihara } & 139.8 & 3.35\end{array}$

Table II. Best values of the parameters obtained by the method explained in the text. 4.2 EXP: 6

For this function $\alpha$ had to be selected first. It was initially taken as 12 and curves of $\epsilon / \mathrm{k}$ versus $T$ generated around $r_{\mathbb{m}}=3.5 \AA$ using the collision integrals from Ref. 1,11 . When $r_{m}$ was varied by about $6 \%$, exactly the same pattern of curves were obtained as for the Lennard-Jones, Fig. 1. The curve for the best value of $r_{\mathrm{m}}$ for $\alpha=12$ was selected as above and shown in Fig. 3 . The procedure was repeated for $\alpha=13,14,15,16$, and 17 with the same results, and corresponding curves for the best values are plotted in Fig. 3. It is seen that there is virtually no difference in the curves so $\alpha=14$ was chosen to agree with Refs. 1, 1l, and 12. Best values of $\epsilon / \mathrm{k}$ and $r_{\mathrm{m}}$ were thus selected, (Table II) as outlined above and a deviation curve plotted, Fig. 2. The Exp: 6 function does not reproduce the data at high temperatures as well as the Lennard-Jones.

\subsection{KIFARA}

The variation of the reduced parameter $\gamma$ (with $\gamma$ defined as $a / \sigma$ ) was first investigated, letting $\gamma$ be $0.1,0.2,0.3,0.4$, and $0.5(\gamma=0$ is equivalent to the Lennard-Jones $)$. The tables from Ref. 3 were used. It was found that the Lennard-Jones pattern of curves was only observed when $\gamma=0.1$ and 0.2 ; the other values gave different patterns when $\sigma$ was varied, $\epsilon / \mathbf{k}$ was always high at the lower temperatures. Typical curves are shown in Fig. 4 and 5. $\gamma$ was taken as $0.1[3,22]$ and a best value of $\epsilon / \mathrm{k}$ found by fitting to $293^{\circ} \mathrm{K}$ as before, Table II. The deviation curve is shown in Fig. 2 . It is seen that the Kihara appears to be slightly better than the Lennard-Jones overall and decidediy superior at low temperatures. 


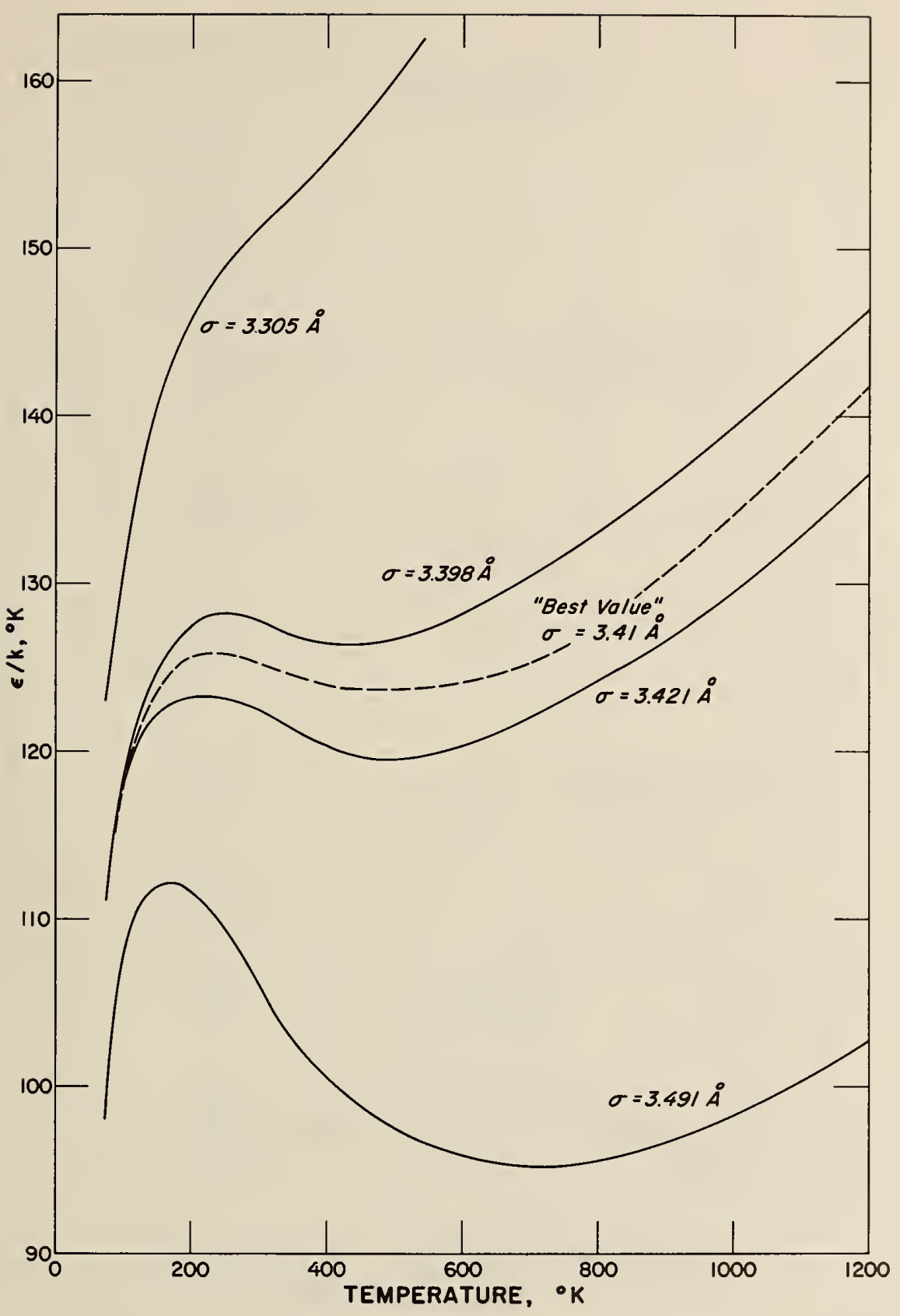

[-56154

Fig. 1. Variation of $\epsilon / \mathrm{K} \quad{ }^{\circ} \mathrm{K}$ versus $T^{\circ} \mathrm{K}$ for various best values of $\sigma$, selected by other authors, using the Lennard-Jones potential function. The dotted curve represents the best value of $\sigma$ selected here. Similar curves were obtained for the Exp: 6 and Kihara functions when $R$ was varied, except when $\gamma=0.3,0.4$ and 0.5 . 


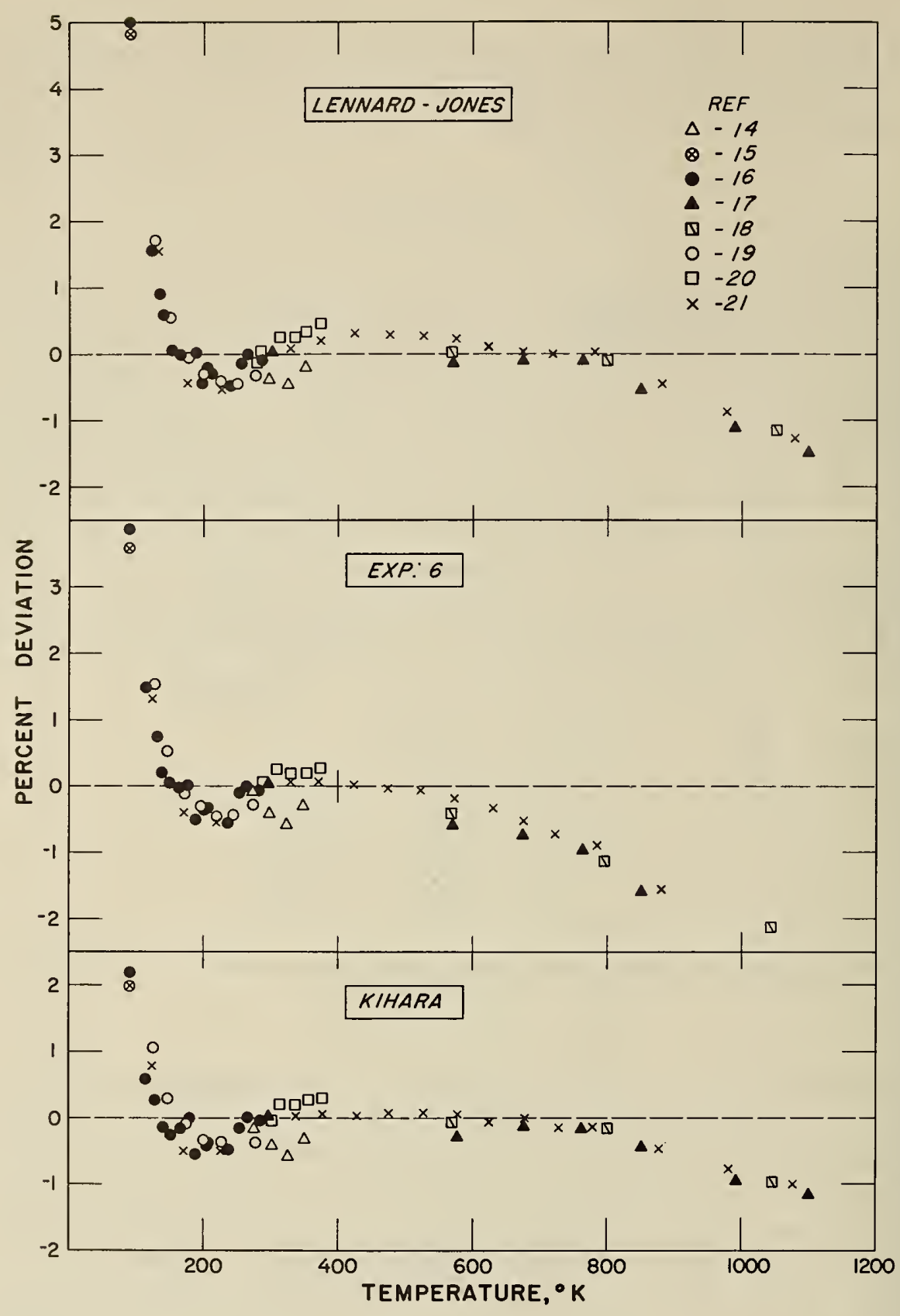

B- 56.155

F1g. 2. Percentage deviation plots $\left[\left(\frac{\eta_{0 \times p}-\eta_{\text {calc }}}{\tau_{\text {cal }}}\right) \times 100\right]$ of experimental and calculated viscosity coefficients for the three potential functions using the best values from Table II (Note: data from Ref. 14 is obtained by extrapolation to a pressure of one atmosphere). 

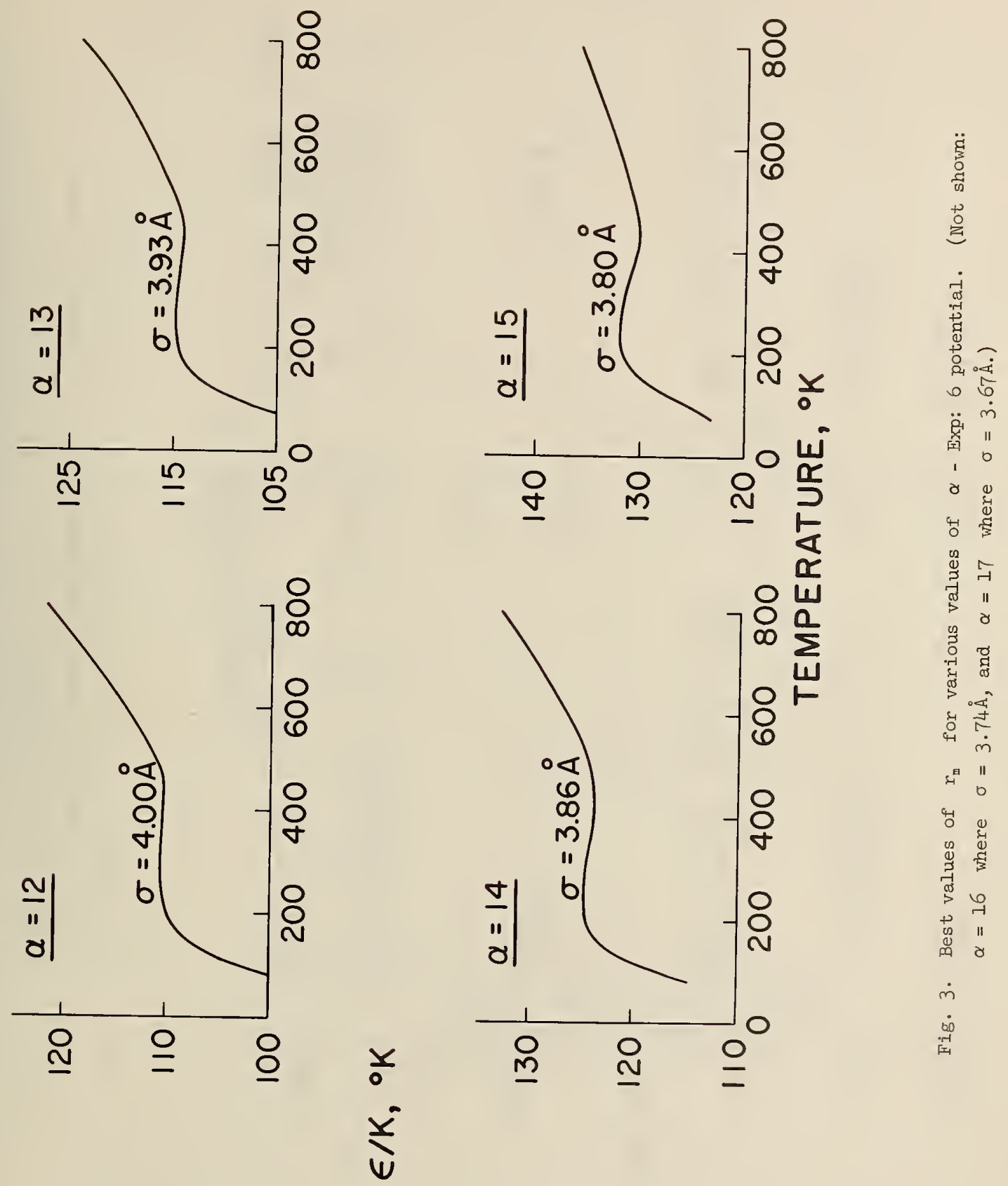

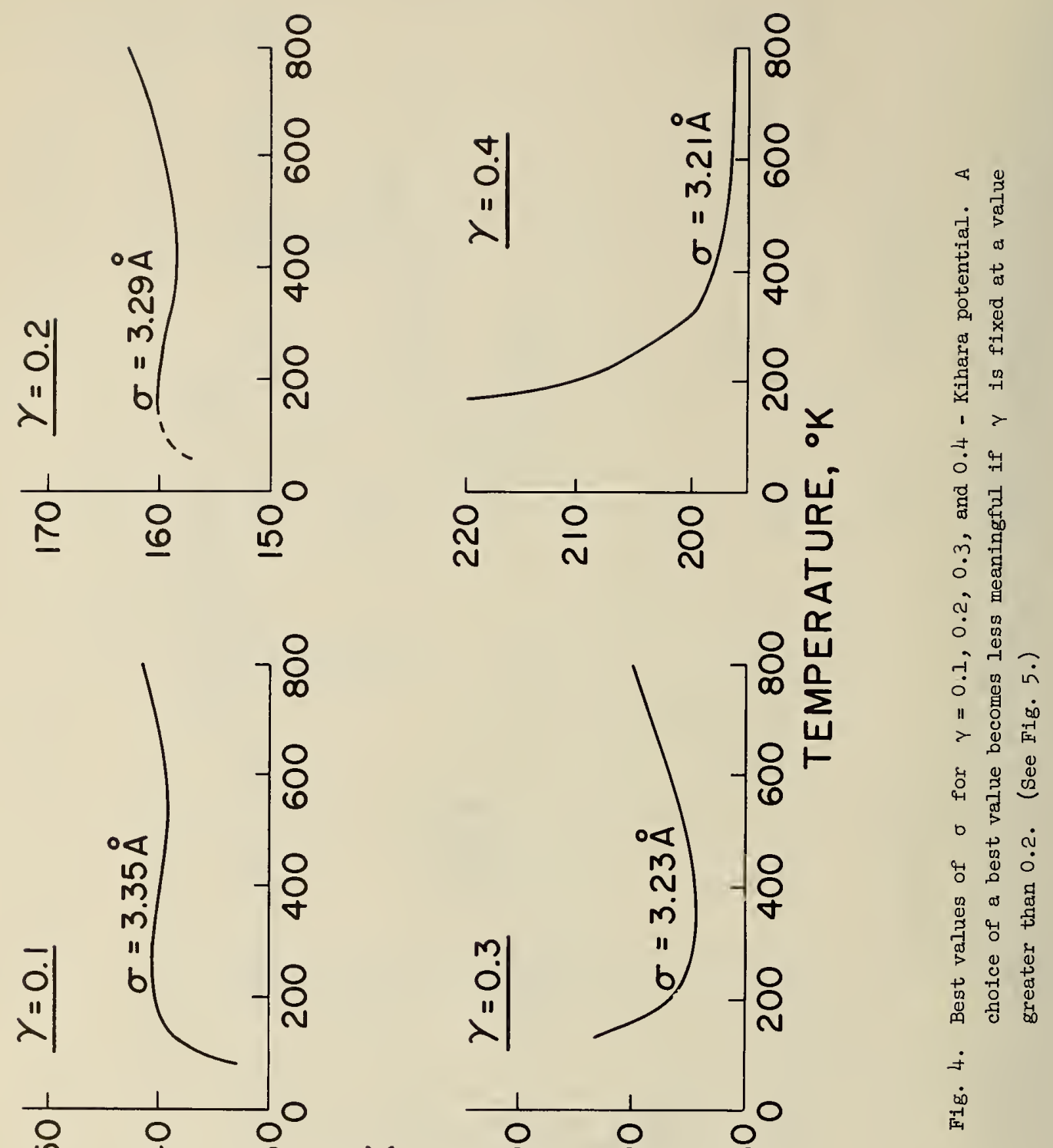


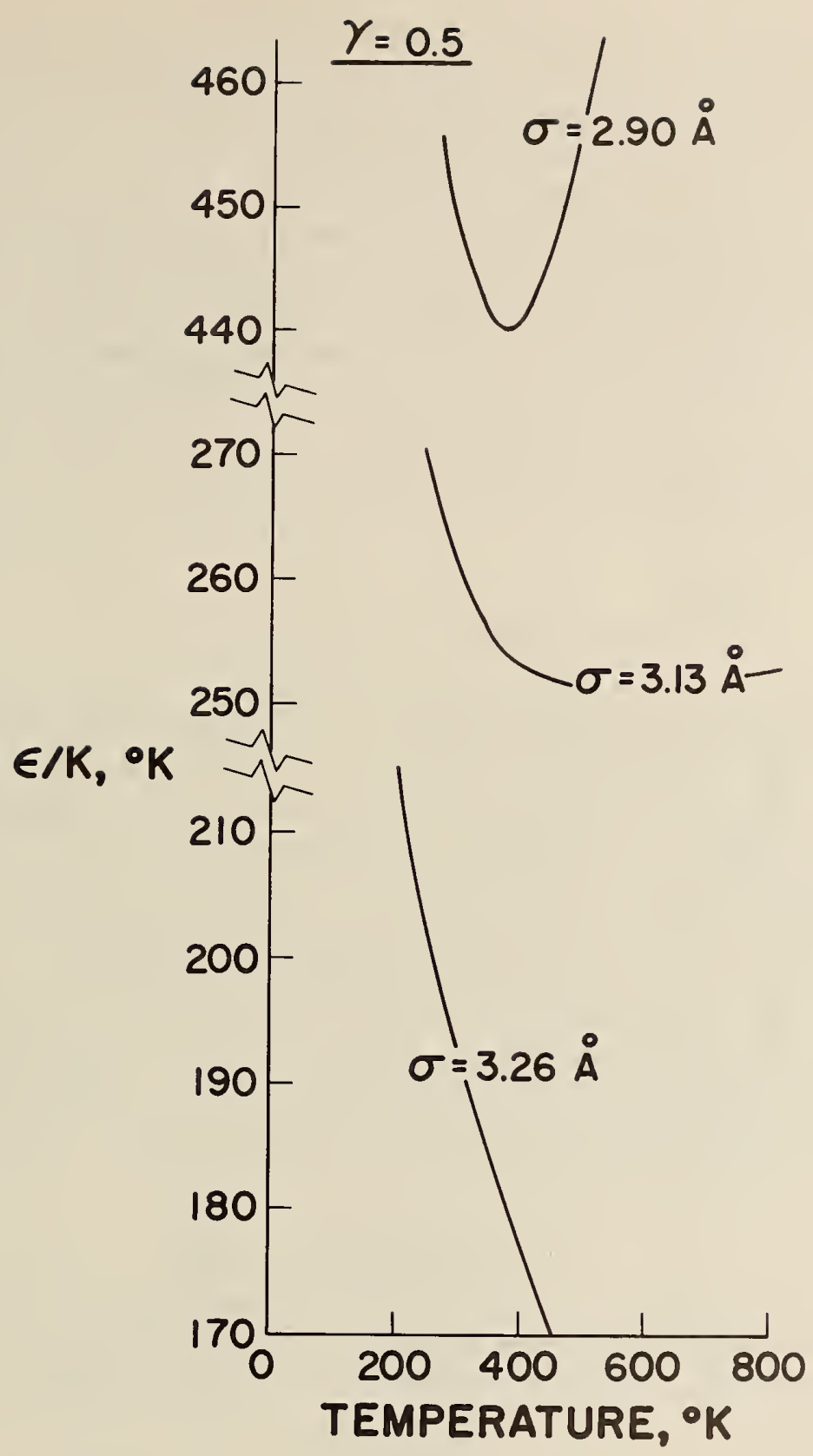

Fig. 5. The pattern of curves for $\gamma=0.5$ is illustrated by $\sigma=2.90 \AA$, $\sigma=3.13 \AA$ and $\sigma=3.26 \AA$. 
The conclusion from the above is that care must be taken to rationalize the choice of $R$ and $\varepsilon / k$ when comparing one potential function with another. It is seen that less than a $6 \%$ variation in $R$ will make comparisons over a wide temperature range meaningless, a factor neglected by many authors. It is shown here that for argon the Lennard-Jones gives a much better correlation with experiment than before realized and that the Kihara potential is even better. In fact, in the temperature range 100 to $1500^{\circ} \mathrm{K}$, the correlation is almost as good as could be obtained from an empirical polynomial fit [23]. The deviations at high and low temperatures have not been satisfactorily explained. It has been suggested that the experimental viscosity coefficients are too low at the higher temperatures [5, 11]. It will be shown that correlation curves for the thermal conductivity and self-diffusion coefficients tend to support this. The deviations at the lower temperatures are not likely to be caused by quantum effects and the reason is still really unsolved (see, however, Ref. 5). Although the Kihara is thus recommended as the most realistic function it is clear that, in practice, there is really very little to choose from among these functions. In fact, the method illustrates the arbitrariness in choosing a potential function.

\section{THERMAL CONDUCTIVITY}

The experimental and kinetic theory viscosity coefficients have been shown to be satisfactorily correlated with the Kihara potential and the parameters given in Table II. The corresponding thermal conductivity expression, Eq. 5 should be equally applicable for dilute argon. This was tested by plotting the deviation curve of the resulting theoretical coefficient from the experimental coefficient, Fig. 6 (the experimental values, at one atmosphere, were taken from Refs. 24-32). As is well known the scatter in these experimental values is large, especially at temperatures outside the range 200 to $600^{\circ} \mathrm{K}$. It is seen, however, that the kinetic theory, with the Kihara potential gives an adequate correlation. Of course, as Eq. 5 was used, the same deviations observed with the viscosity correlation will be introduced into the thermal conductivity correlation. This is apparent at low temperatures, but not at high temperatures. The experimental viscosity coefficients at these high temperatures may be low, but thermal conductivity data are not reliable enough to give any definite conclusions. Thus, tables of the thermal conductivity coefficients computed with the Kihara are reasonable above $100^{\circ} \mathrm{K}$, a.though there must be uncertainty above $1200^{\circ} \mathrm{K}$.

\section{SELF-DIFFUSION}

For completeness the self-diffusion coefficient, Eq. 6, was included and a deviation curve plotted, Fig. 7. The experimental data, taken from Refs. 33-37, are scarce and so the correlation, although reasonably satisfactory, is not very meaningful.

\section{CONCLUSION}

The above three deviation plots (Figs. 2, 6, and 7) indicate that the kinetic theory expressions for the transport coefficients can be used to compute tables for dilute argon, at least to within about four percent between 100 and $1200^{\circ} \mathrm{K}$. Thus, tables of the viscosity and thermal conductivity coefficients for temperatures from 100 to $2000^{\circ} \mathrm{K}$ have been computed and are given in Appendix I. It is recognized that the error in any fitted function tends to increase as the independent variable, temperature in this case, increases beyond the range of the data.

\section{ACKNOWLEDDGEMEINT}

This work was supported by a grant from NASA. Thanks are given to Gregg Childs for assistance with the preparation of the data, and to Max Kein, J. G. Hust, R. B. Stewart, and R. D. McCarty for valuable discussions. 


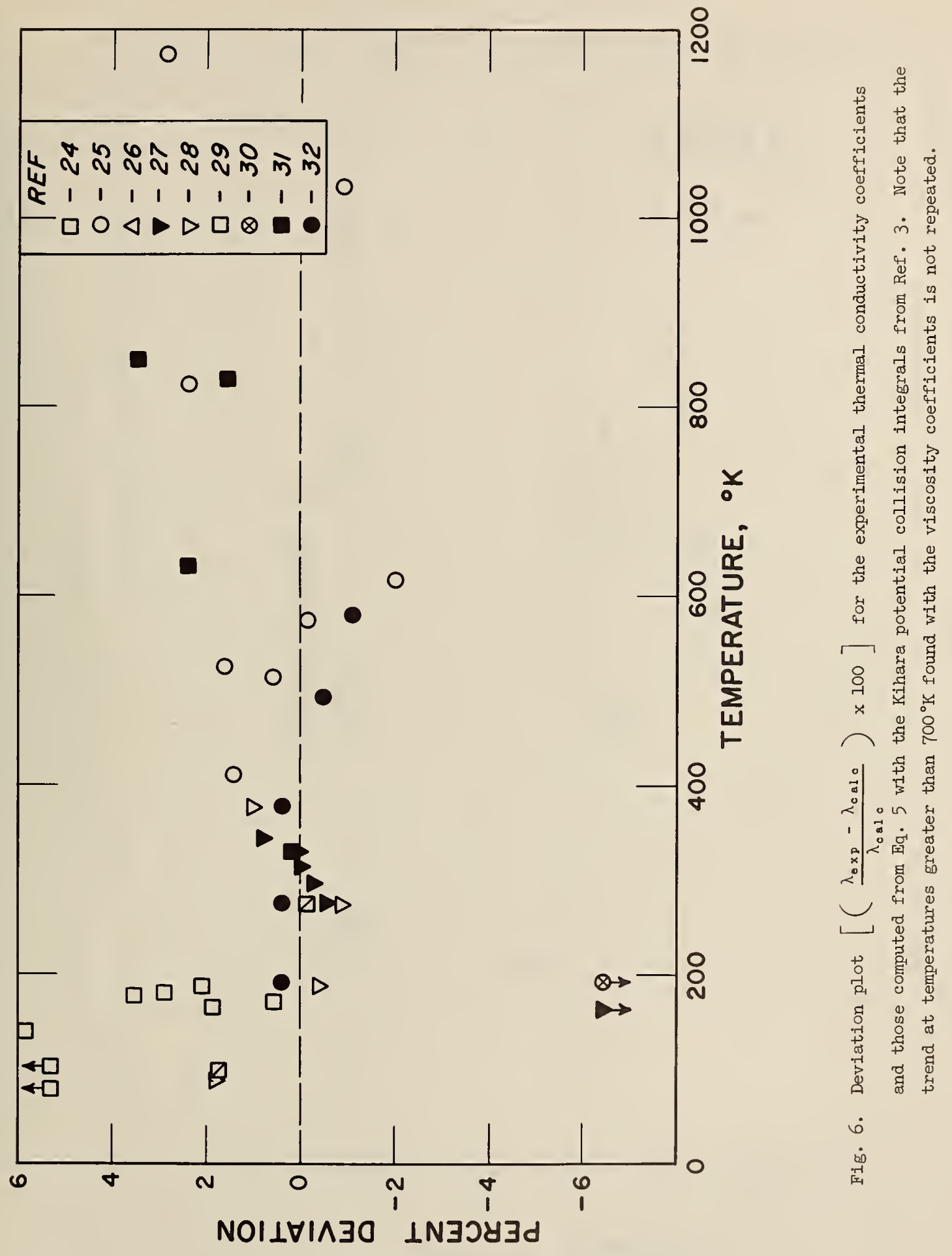




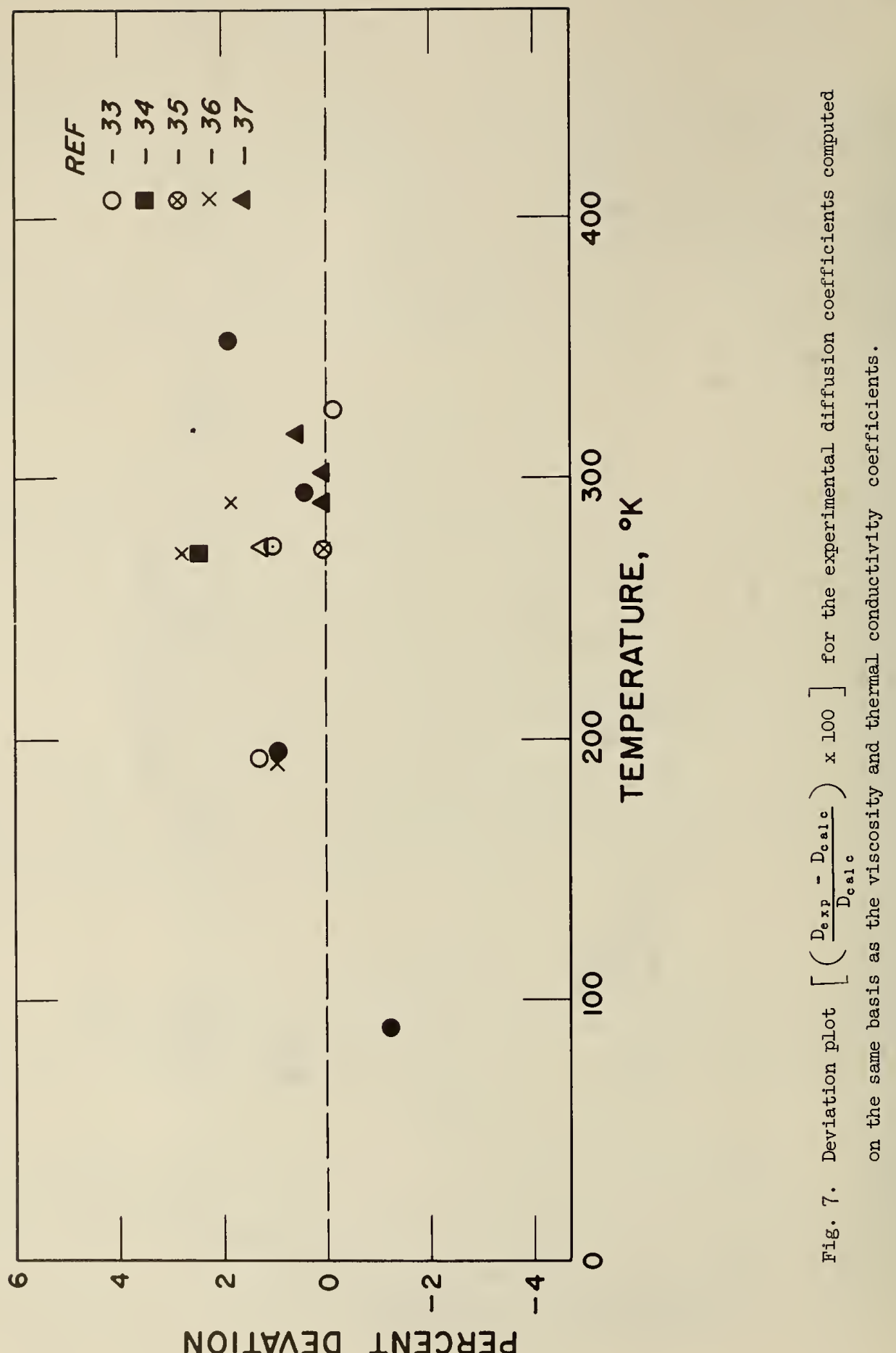




\section{APPHINDIX I}

THE VISCOSITY AND THERMAL CONDUCTIVITY COEFFICIENTS OF DILUTE ARGON FROM 100 TO $2000^{\circ} \mathrm{K}$

The tables were computed from Eqs. 4 and 5 using the Kihara collision integrals from Ref. 3 and letting $\gamma=0.1, \sigma=3.35 \AA$, and $\epsilon / \mathrm{k}=139.8^{\circ} \mathrm{K}$. 


\begin{tabular}{|c|c|c|c|c|c|}
\hline TEMPERATUKE & VISCOSITY & $\begin{array}{l}\text { THERMAL } \\
\text { CONDUCTIVITY }\end{array}$ & TEMPERATURE & VISCOSITY & $\begin{array}{l}\text { THERMAL } \\
\text { CONDUCTIVITY }\end{array}$ \\
\hline \multirow[t]{4}{*}{ K } & $G / C M-S E C$ & $C A L / C M-S E C-D E G$ & $k$ & $G / C M-S E C$ & CAL/CM-SEC-DEG \\
\hline & $\eta \times 10^{6}$ & $\lambda \times 10^{6}$ & & $\eta \times 10^{6}$ & $\lambda \times 10^{\circ}$ \\
\hline & & & $\begin{array}{l}500 \\
510 \\
520 \\
530 \\
540\end{array}$ & $\begin{array}{l}334.9 \\
339.8 \\
344 \cdot 5 \\
349 \cdot 2 \\
353.8\end{array}$ & $\begin{array}{l}62 \cdot 5 \\
63 \cdot 4 \\
64 \cdot 3 \\
65 \cdot 1 \\
66 \cdot 0\end{array}$ \\
\hline & & & $\begin{array}{l}550 \\
560 \\
570 \\
580 \\
590\end{array}$ & $\begin{array}{l}358 \cdot 3 \\
362 \cdot 9 \\
367 \cdot 4 \\
371 \cdot 9 \\
376 \cdot 4\end{array}$ & $\begin{array}{l}66 \cdot 8 \\
67 \cdot 7 \\
68 \cdot 5 \\
69 \cdot 4 \\
70 \cdot 2\end{array}$ \\
\hline 100 & 82.5 & 15.4 & 600 & 380.8 & 71.0 \\
\hline $\begin{array}{l}110 \\
120 \\
130 \\
140\end{array}$ & $\begin{array}{r}90.6 \\
98.7 \\
100.8 \\
114.8\end{array}$ & $\begin{array}{l}16.9 \\
18.4 \\
19.9 \\
21.4\end{array}$ & $\begin{array}{l}610 \\
620 \\
630 \\
640\end{array}$ & $\begin{array}{l}385.1 \\
389.5 \\
393.8 \\
398.0\end{array}$ & $\begin{array}{l}71.8 \\
72.6 \\
73.4 \\
74.2\end{array}$ \\
\hline 150 & 122.7 & 22.9 & 650 & 402.3 & 75.0 \\
\hline $\begin{array}{l}160 \\
170 \\
180 \\
190\end{array}$ & $\begin{array}{l}130.4 \\
138.1 \\
145.7 \\
153.1\end{array}$ & $\begin{array}{l}24.3 \\
25.8 \\
27.2 \\
28.6\end{array}$ & $\begin{array}{l}660 \\
670 \\
680 \\
690\end{array}$ & $\begin{array}{l}406.5 \\
410.6 \\
414.8 \\
418.9\end{array}$ & $\begin{array}{l}75.8 \\
76.6 \\
77.4 \\
78.1\end{array}$ \\
\hline $\begin{array}{l}200 \\
210 \\
220 \\
230 \\
240\end{array}$ & $\begin{array}{l}160.4 \\
167.7 \\
174.6 \\
181.6 \\
188.5\end{array}$ & $\begin{array}{l}29.9 \\
31.3 \\
32.6 \\
33.9 \\
35.2\end{array}$ & $\begin{array}{l}700 \\
710 \\
720 \\
730 \\
740\end{array}$ & $\begin{array}{l}423 \cdot 0 \\
427 \cdot 1 \\
431 \cdot 1 \\
435 \cdot 1 \\
439 \cdot 1\end{array}$ & $\begin{array}{l}78.9 \\
79.7 \\
80.4 \\
81.2 \\
81.9\end{array}$ \\
\hline 250 & 195.2 & 36.4 & 750 & 443.1 & 82.6 \\
\hline $\begin{array}{l}260 \\
270 \\
280 \\
290\end{array}$ & $\begin{array}{l}201.8 \\
208 \cdot 3 \\
224.7 \\
220.9\end{array}$ & $\begin{array}{l}37.6 \\
38.9 \\
40.0 \\
41.2\end{array}$ & $\begin{array}{l}760 \\
770 \\
780 \\
790\end{array}$ & $\begin{array}{l}447.1 \\
451.0 \\
454.7 \\
458.4\end{array}$ & $\begin{array}{l}83.4 \\
84.1 \\
84.8 \\
85.5\end{array}$ \\
\hline $\begin{array}{l}300 \\
310 \\
320 \\
330 \\
340\end{array}$ & $\begin{array}{l}227.1 \\
233.3 \\
239.4 \\
245.2 \\
251.0\end{array}$ & $\begin{array}{l}42.4 \\
43.5 \\
44.6 \\
45.7 \\
46.8\end{array}$ & $\begin{array}{l}600 \\
610 \\
820 \\
830 \\
840\end{array}$ & $\begin{array}{l}462.5 \\
466.3 \\
470.0 \\
473.8 \\
477.6\end{array}$ & $\begin{array}{l}86.3 \\
87.0 \\
87.7 \\
88.4 \\
89.1\end{array}$ \\
\hline $\begin{array}{l}350 \\
360 \\
370 \\
380 \\
390\end{array}$ & $\begin{array}{l}256.7 \\
262.4 \\
268.1 \\
273.6 \\
279.1\end{array}$ & $\begin{array}{l}47.9 \\
48.9 \\
50.0 \\
51.0 \\
52.1\end{array}$ & $\begin{array}{l}850 \\
860 \\
870 \\
680 \\
890\end{array}$ & $\begin{array}{l}481 \cdot 3 \\
485.0 \\
488 \cdot 7 \\
492 \cdot 4 \\
496 \cdot 1\end{array}$ & $\begin{array}{l}89 \cdot 8 \\
90.5 \\
91 \cdot 2 \\
91 \cdot 9 \\
92 \cdot 5\end{array}$ \\
\hline 400 & 284.5 & 53.1 & 900 & 499.8 & 93.2 \\
\hline 410 & 289.8 & 54.1 & 410 & 503.5 & 93.9 \\
\hline $\begin{array}{l}420 \\
430\end{array}$ & $\begin{array}{l}29.11 \\
300 \cdot 4\end{array}$ & $\begin{array}{l}55 \cdot 0 \\
56 \cdot 0\end{array}$ & $\begin{array}{l}420 \\
930\end{array}$ & $\begin{array}{l}507 \cdot 1 \\
510 \cdot 7\end{array}$ & $\begin{array}{l}94 \cdot 6 \\
95 \cdot 3\end{array}$ \\
\hline 440 & 305.5 & 57.0 & 940 & $514 \cdot 4$ & $95 \cdot 9$ \\
\hline 450 & 310.5 & 57.9 & 950 & 518.0 & 96.6 \\
\hline $\begin{array}{l}460 \\
470 \\
480 \\
490\end{array}$ & $\begin{array}{l}315.5 \\
320.5 \\
3.25 .4 \\
3.30 .3\end{array}$ & $\begin{array}{l}58.9 \\
59.8 \\
60.7 \\
61.6\end{array}$ & $\begin{array}{l}960 \\
970 \\
980 \\
990\end{array}$ & $\begin{array}{l}521 \cdot 5 \\
525 \cdot 1 \\
528 \cdot 7 \\
532.2\end{array}$ & $\begin{array}{l}97.3 \\
97.9 \\
98.6 \\
99.3\end{array}$ \\
\hline
\end{tabular}

* Calculated for the dilute gas by the Kihara potential, with $\gamma=.1, \sigma=3.35 \AA, \varepsilon / \mathrm{k}=139.8^{\circ} \mathrm{K}$. Figure 11 defines temperature and pressure range for the dilute gas. 


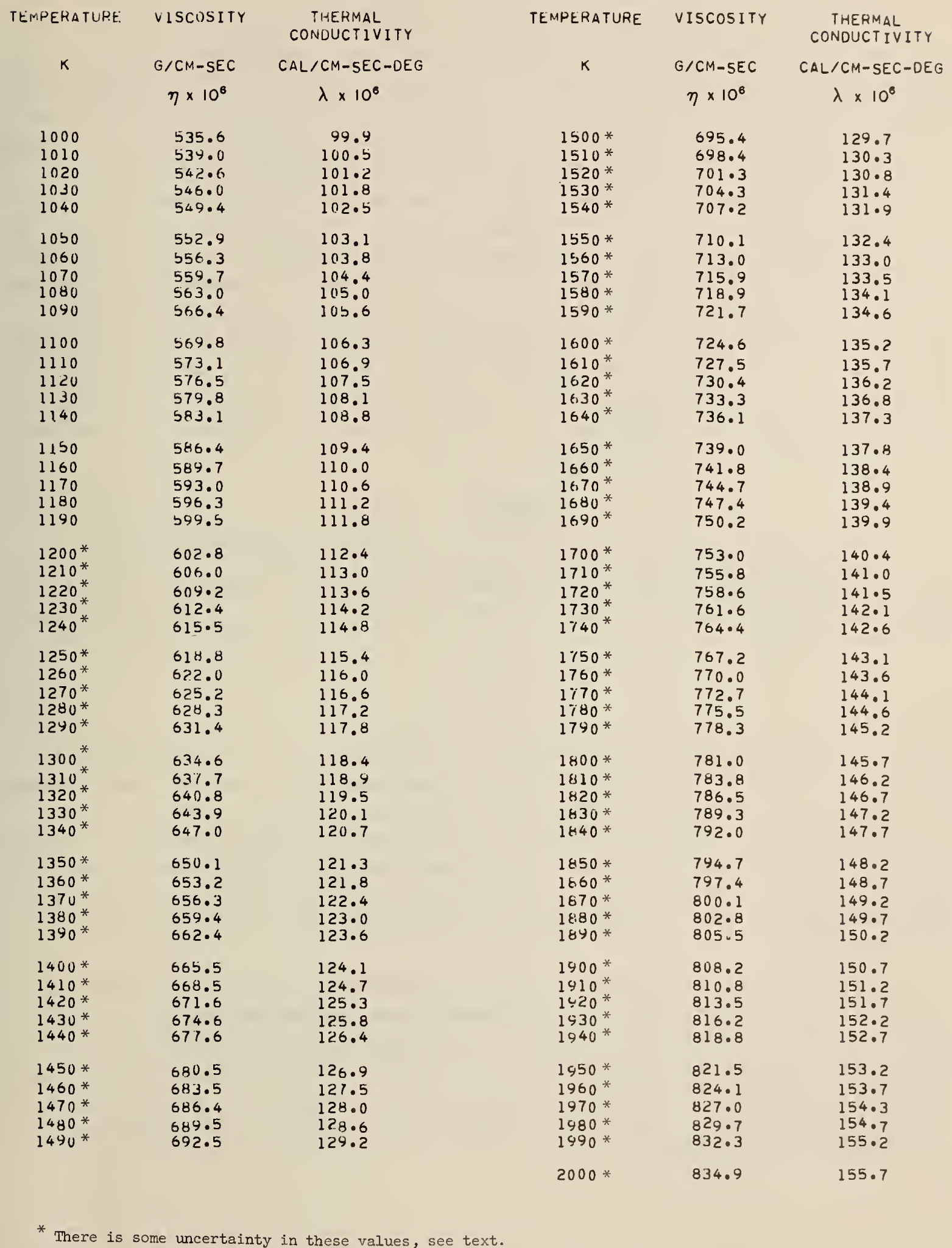




\section{APPENDIX II}

\section{AN ESTIMATE OF THE EXXTENT OF VALIDITY OF THE TRANSPORT PROPERTY TABLES}

It is interesting to estimate the experimental conditions for which the tables are valid. These tables are, of course, only applicable when the gas is dilute, where a dilute gas can be defined as a gas in which only binary molecular collisions are of consequence: in other words, the gas dynamics and the intermolecular interactions are completely determined by the collisions and interactions between pairs of molecules alone. The gas must not be so rarefied, however, that gas-wall collisions are of any account. Furthermore, the viscosity coefficient, iq. 4, must be independent of pressure, Thus, the tables are inapplicable for experimental conditions where Eq. 4 no longer reproduces the experimental data (to within about $0.5 \%$ in the temperature range of 100 to $1500^{\circ} \mathrm{K}$ ). Also if Eq. 4 does not reproduce the data the gas cannot be regarded as dilute as defined. Therefore, a straightforward procedure could be to compare experimental viscosity coefficients at pressures greater than one atmosphere with the equivalent theoretical values from Eq. 4 at the corresponding temperatures, and observe when the percentage deviation becomes appreciable. This was indeed done with the experimental data from Refs. 1, 14, 38-40 and percentage deviations calculated for the given temperatures and pressures. A qualitative, but simple, way to examine the results was to plot the percentage deviations versus a reduced mean free path $\lambda_{R}$. As the results were only qualitative, the elementary kinetic theory expression for the mean free path was used:

$$
\lambda=\frac{3 \eta R}{P \bar{V} M} \quad \mathrm{~cm},
$$

where $R$ is the gas constant per mole. $P$ the pressure in dynes and $\bar{V}=(8 \mathrm{RT} / \pi \mathrm{M})^{1 / 2}$. $\lambda$ was reduced by dividing by the mean free path of argon at one atmosphere and at $293^{\circ} \mathrm{K}, \quad\left(\eta_{293^{\circ}}=2.23 \times 10^{-4} \mathrm{~g} \mathrm{~cm}^{-1}\right.$ $\left.\sec ^{-1}\right)$. We then obtain:

$$
\lambda_{\mathrm{R}}=257 \eta(\mathrm{T})^{1 / 2} / \mathrm{P}
$$

where $\eta$ is the viscosity coefficient at temperature $T$ and pressure $P$ ( $P$ now in atmospheres). Figure 8 shows the plot and it is seen that there is an appreciable rise at $\lambda_{R}=0.07$ and percentage deviation $=1 \%$. It is reasonable to take this point as the extent of validity of Eq. 4 and as the limit of dilution. The limiting value of $\lambda$ was then used (Eq. 7) to construct Fig. 9 which shows an approximate limiting P-T curve above which argon cannot be considered dilute. A curve for a $2 \%$ deviation $\left(\lambda_{\mathrm{R}}=0.05\right)$ is also included. Unfortunately, the experimental work was not carried out at high temperatures and the higher temperature data available (Ref. 38) do not agree too well with other woxkers, Fig. 8.

The above exercise is very qualitative; even for argon there is uncertainty in the values of force-constants, the experimental data are not as extensive as desired and obviously Eq. 7 is only approximate. Also, more seriously, one cannot be sure how the failure of the potential function to exactly reproduce the data, especially at the higher temperatures, is contributing to the rise in the curve in Fig. 8. However, Fig. 9 is certainly reasonable and it is expected that similar curves would approximately represent the limit of dilution for simple gases at temperatures and pressures removed from the critical and boiling regions. 


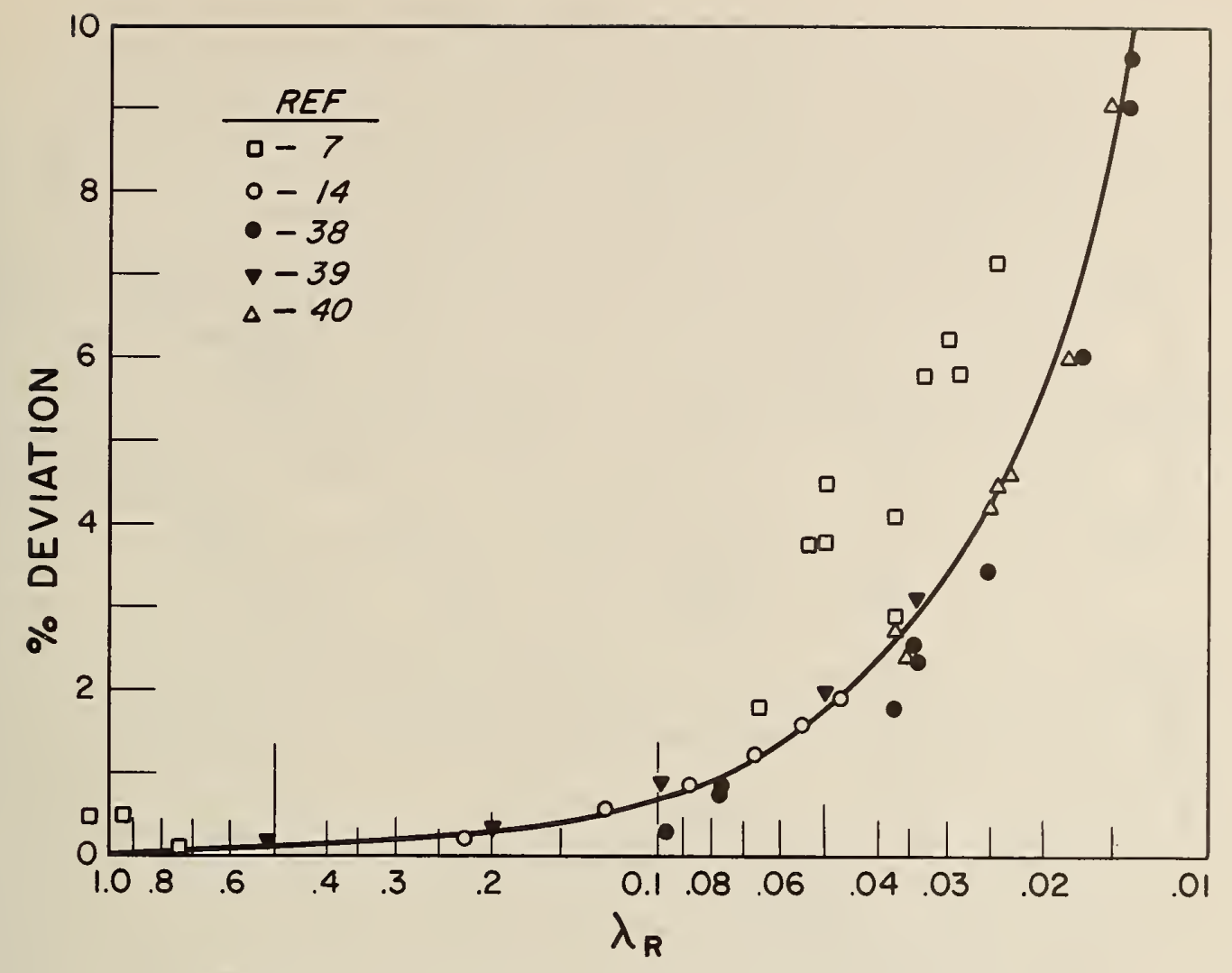

Fig. 8. Plot of the percentage deviation of the experimental and theoretical viscosity coefficients calculated from $\mathrm{Eq}$. 4 versus the reduced mean free path $\lambda_{R}$, Eq. 8 . 


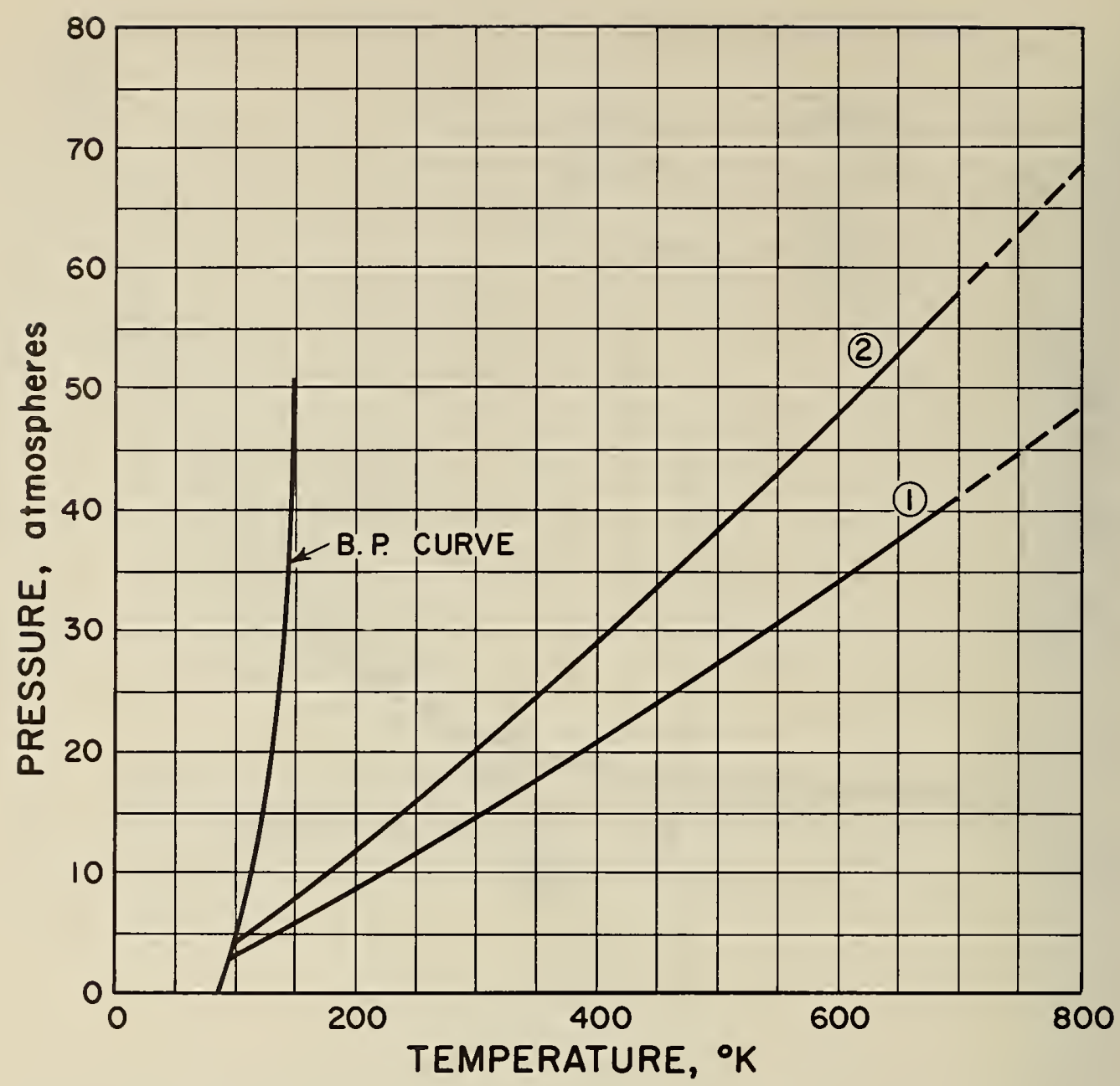

Fig.9. Plot of the pressure versus temperature limiting dilution curves for argon. The gas can be assumed to be dilute for all pressures and temperatures below curve 1 . Curve $I$ was constructed by comparing experimental viscosity coefficients with the theoretical, Eq. 4, and is the curve for a $1 \%$ deviation (See explanation in the text). Curve 2 which represents a $2 \%$ deviation between theory and experiment is included for comparison. Curve 1 represents a constant density curve of $0.025 \mathrm{~g} \mathrm{~cm}^{-3}$. 
11. APPENDIX III (With A. L. $\operatorname{Gosman}^{\dagger}$ )

THE SELECTION OF FORCE CONSTANTS

Force constants, for a particular potential function, are often determined from as many different experimental sources as possible $[1,2,4]$, but it is well known that constants obtained in this general way often lead to anomalous results when they are applied to a single experiment. For example, values of the constants found from, say, equation of state, Joule-Thomson, or crystal structure data, when applied to the transport coefficients do not always give as good results as the values of the constants determined from transport data alone. This is to be expected because the potential function is not exact. The inconsistency has not been discussed quantatively (see, however, Ref. 4I).

The above can be illustrated by comparing the curves for the variation of $\epsilon / k$ with $T$ for the Lennard-Jones at several values of $\sigma$ (Fig. 1) with equivalent curves calculated from second virial coefficients, $\mathrm{B}(\mathrm{T})$,

$$
\begin{aligned}
B(T) & =b_{0} B^{*}\left(T^{*}\right) \\
b_{0} & =\frac{2}{3} \pi N \sigma^{3}
\end{aligned}
$$

where $N=$ Avagadro's number and $B^{*}\left(T^{*}\right)$ is the reduced second virial at the reduced temperature $T^{*}$. (In Ref. 22, $\epsilon / k$ and $b_{0}$ were found to depend on the temperature but the temperature range was restricted from 90 to $400^{\circ} \mathrm{K}$.)

It was straightforward to find the variation of $\epsilon / k$ with $T$ at constant $\sigma$ by following the viscosity procedure and referring to the reduced second virials in Ref. 1 . The experimental data are given in Ref. 22. The resulting curves are shown in Fig. 10. When compared to Fig. 1 over a similar temperature range it is seen that the pattern is different and that the second virial does not appear to be as sensitive to a change in $\sigma$ as the viscosity coefficient. A "best value" for $\epsilon / k$ in the 90 to $400^{\circ} \mathrm{K}$ temperature range is approximately $\epsilon / \mathrm{k}=119^{\circ} \mathrm{K}$. Thus, according to Figs. 1 and 10 it would be best not to interchange the values of the parameters. However, it is instructive to see if a less sensitive relation exists between $\eta$ and $B(T)$. $\eta$ and $B(T)$ can be related if a common $\epsilon / k$ exists because from Eqs. 4 and 9 ,

$$
1 / \Omega^{(2,2)^{*}}\left(T^{*}\right)=F\left(B^{*}\left(T^{*}\right)\right)
$$

From the experimental data one can calculate,

$$
1 / \Omega^{(2,2) *}\left(T^{*}\right)=\eta_{6 \times p} \frac{10^{7} \sigma^{2}}{266.93}(M T)^{1 / 2}
$$

and

$$
\mathrm{B}^{*}\left(\mathrm{~T}^{*}\right)=\mathrm{B} \circ \mathrm{xp} / \frac{2}{3} \pi \mathrm{N} \sigma^{3}
$$

This has been done for three values of $\sigma$ and the results drawn as points in Fig. 11 . The full curve in Fig. 11 represents Eq. 10 constructed from the theoretical tables in Refs. 1 and 3 . The sources of the viscosity coefficient experimental data are given in Section 4 and the second virial in Ref. 22. It is seen that when $\sigma=3.42 \AA$, agreement between theory and experiment is excellent and thus it would appear that a consistent pair of values for $\epsilon / k$ and $\sigma$ would result from independent examination of both viscosity and second virial experimental data, but clearly, this latter method is not as sensitive as the former.

† Present address: Department of Mechanical Engineering, Wayne State University, Detroit, Michigan. 


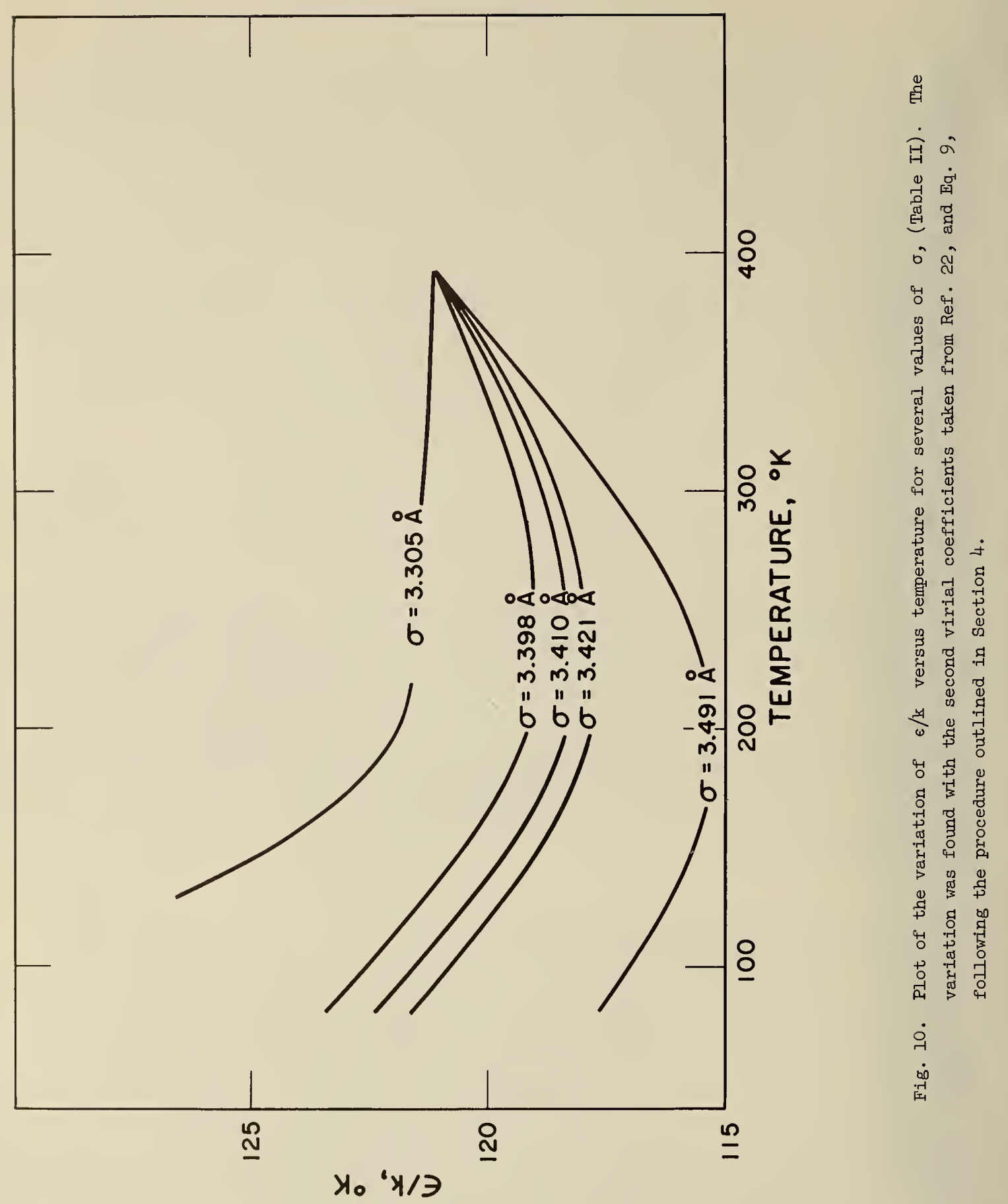




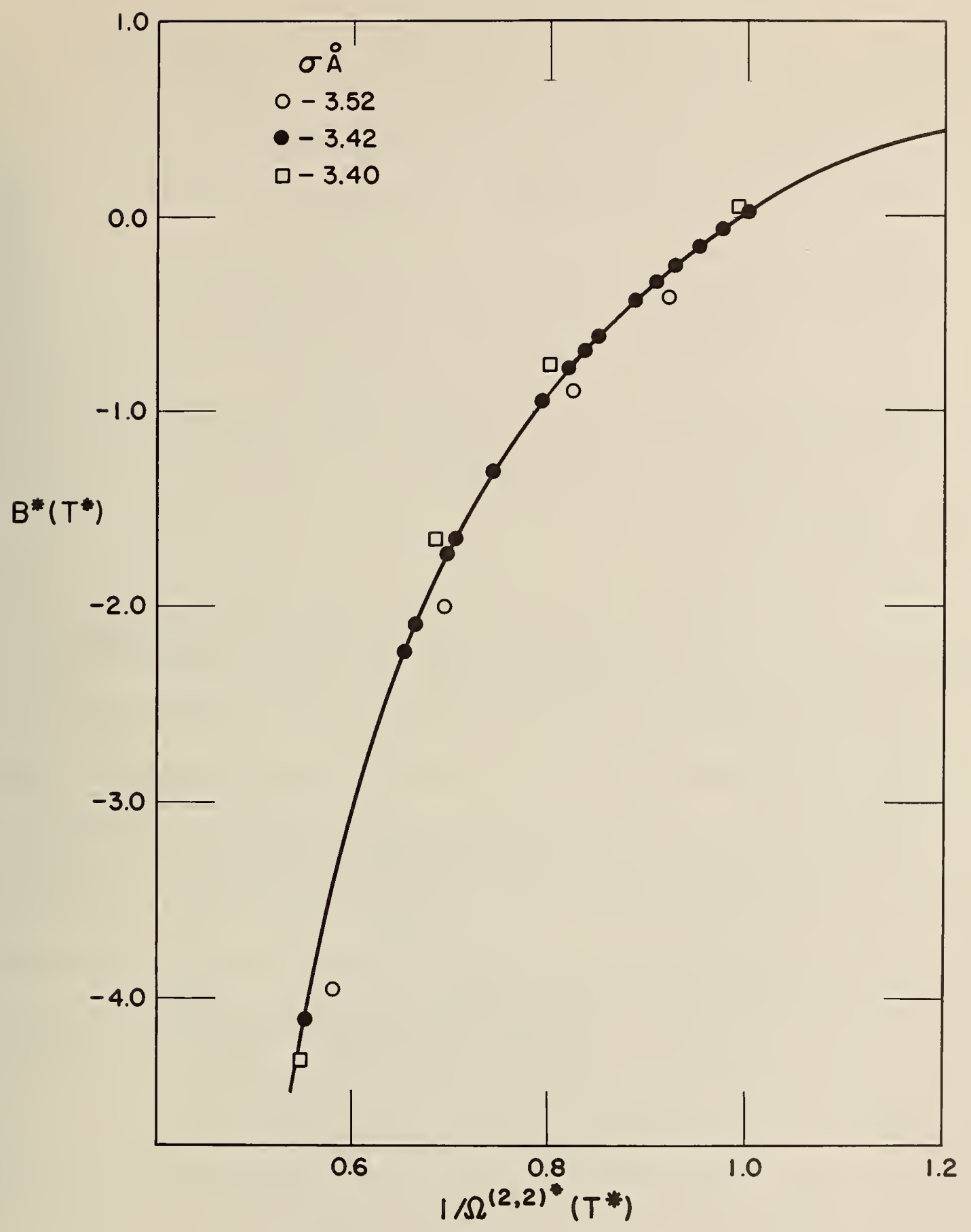

Fig. 11. Plot of $B^{*}\left(T^{*}\right)$ versus $1 / \Omega^{(2,2) *}\left(T^{*}\right)$. The solid curve was generated from Eq. 10 using the second virial and collision integral tables from Refs. 1 and 3. The points represent the curve from experimental data with three values of $\sigma$. 


\section{REFERENCES}

1. J. O. Hirschfelder, C. F. Curtiss, and R. B. Bird, MOLECULAR THEORY OF GASES AND LIQUIDS, John Wiley \& Sons, New York (1964) Second Printing.

2. R. A. Svehla, Estimated Viscosities and Thermal Conductivities of Gases at High Temperatures, Natl. Aeronaut. Space Admin. Tech. Rept. R-132 (1962), DDC AD 272963.

3. J. A. Barker, W. Fock, and F. Smith, Calculation of Gas Transport Properties and the Interaction of Argon Atoms, Phys. Fluids I, 897-903 (196́4).

4. J. Hilsenrath, C. W. Beckett, W. S. Benedict, L. Fano, H. J. Hoge, J. F. Masi, R. L. Nuttall, Y. S. Touloukian, and H. W. Woolley, Tables of Thermal Properties of Gases, Natl. Bur. Standards Circ. No. 564 (Nov 1955).

5. R. J. Munn and F. J. Smith, Interaction of the Inert Gases II, Univ. Maryland, Inst. Molecular Phys. IMP-NASA-47 (May 1965)

6. J. H. Milligan and P. E. Liley, Lennard-Jones Potential Parameter Variation as Determined from the Viscosity Data for Twelve Gases, Am. Soc. Mech. Engrs. Paper No. 64-HT-20 (1964).

7. J. Kestin and J. H. Whitelaw, A Relative Determination of the Viscosity of Several Gases by the Oscillating Disk Method, Physica 29, 335-56 (1963).

8. E. Whalley and W. G. Schneider, The Lennard-Jones 12-6 Potential and the Viscosity of Gases, J. Chem. Phys. 20, 657-61. (1.952).

9. J. S. Rowlinson, A Test of Kihara's Intermolecular Potential, Mol. Phys. 2, No. 2, $197-98$ (1965).

10. J. P. O'Connell and J. M. Prausnitz, Applications of the Kihara Potential to Thermodynamic and Transport Properties of Gases, ADVANCES IN THERMOPHYSICAI PROPERTIES AT EXTREME TEMPERATURES AND PRESSURES, 19-31 Am. Soc. Mech. Engr., New York (1965).

11. E. A. Mason and W. E. Rice, The Intermolecular Potentials for Some Simple Non-polar Molecules, J. Chem. Phys. 22, 843-51 (1954).

12. A. G. de Rocco and J. O. Halford, Intermolecular Potentials of Argon, Methane and Ethane, J. Chem. Phys. 28, 1152-54 (1958).

13. H. J. M. Hanley, Comparison of the Lennard-Jones, Exp: 6, and Kihara Potential. Functions Using Viscosity Data of Dilute Argon, to be published in J. Chem. Phys. 1966.

14. A. Michels, A. Botzen, and W. Schuurman, The Viscosity of Argon at Pressures up to 2000 Atmospheres, Physica 20, 1141-48 (1954).

15. A. Van Itterbeek and O. Van Paemel, Measurements on the Viscosity of Argon Gas at Room Temperature and Between $90^{\circ}$ and $55^{\circ} \mathrm{K}$, Physica 5, 1009-11 (1938).

16. H. L. Johnston and E. R. Grilly, Viscosities of Carbon Monoxide, Helium, Neon, and Argon Between $80^{\circ}$ and $300^{\circ} \mathrm{K}$ Coefficients of Viscosity, J. Phys. Chem. 46, 948-63 (1942).

17. M. Trautz and R. Zink, Die Reibung, Warmeleitung und Diffusion in Gasmischungen. XII. Gasreibung bei hoheren Temperaturen, (The Viscosity, Heat Conduction and Diffusion of Gas Mixtures. XII. The Viscosity of Gases at High Temperatures), Ann. Physik I, 427-52 (1930).

18. V. Vasilesco, Recherches Experimentales sur la Viscosite des Gaz aux Temperatures Elevees, (Experimental. Research on the Viscosity of Gas at High Temperatures), Ann. Phys. (Paris) 20, 137-76 (1945).

19. G. P. Filippova and I. P. Ishkin, The Viscosity of Air, Nitrogen, and Argon at Low Temperatures and at Pressures up to 150 Atmospheres, Inzh. Fiz. Zh. Akad. Nauk Belorussk SSR 4, 105-09 (1961).

20. R. Wobser and F. Müiler, Die innere Reibung von Gases und Dämpfen und ihre Messung im HöpplerViskosimeter, (The Viscosity of Gases and Vapors and their Measurement with the Hoppler Viscometer), Kollo1d-Beih. 52, 165-276 (1.941).

21. F. G. Keyes, The Heat Conductivity, Viscosity, Specific Heat and Prandtl Numbers for Thirteen Gases, Mass. Inst. of Technol., Proj. Squid, Tech. Rept. No. 37 (1952), DDC ATI 167173.

22. A. L. Gosman, Thermodynamic Properties of Argon in the Liquid and Gaseous State for Temperatures from the Triple Point to $300^{\circ} \mathrm{K}$ and Pressures to 1.000 Atmospheres, State Univ. of Iowa, Iowa City, Ph. D. Thesis (1965). 
23. Thermophysical Properties Research Center, DATA BOOK, Vol. 2, Purdue University, Lafayette, Ind. (1964).

24. F. G. Keyes, Thermal Conductivity of Gases, Trans. ASME 77, 1395-96 (1955).

25. F. G. Keyes and R. G. Vines, The Thermal Conductivity of Nitrogen and Argon, J. Heat Transfer 87, No. 2 , $177-83(1965)$.

26. A. Michels, J. V. Sengers, and L. J. M. Van de Klundert, The Thermal Conductivity of Argon at Elevated Densities, Physica 29, 149-60 (1963).

27. A. Unlir, Thermal Conductivity of Fluid Argon and Nitrogen, J. Chem. Phys . 20, 463-72 (1952).

28. A. Eucken, Uber die Temperaturabhangigkeit der Warmeleitfahigkeit, einiger Gase, (Concerning the Temperature Dependence of Thermal Conductivity of Several Gases), Physik Z. 12, 1101-17 (1911).

29. H. Ziebland, and J. T. A. Burton, The Thermal Conductivity of Nitrogen and Argon in the Liquid and Gaseous States, Brit. J. Appl. Phys. 9, 52-59 (1958).

30. L. D. Ikenberry and S. A. Rice, Kinetic Theory of Dense Fluids. XIV. Experimental and Theoretical Studies of Thermal Conductivity in Liquid Ar, $\mathrm{Kr}$, Xe and $\mathrm{CH}_{4}, \mathrm{~J}$. Chem. Phys. 39, 1561-71 (1963).

31. A. J. Rothman, Thermal Conductivity of Gases at High Temperatures, U. S. Atomic Energy Comm. UCRL 2339, 8-114 (1953).

32. W. G. Kannuluik and E. H. Carman, The Thermal Conductivity of Rare Gases, Proc. Phys. Soc. (London) B65, 701-09 (1952).

33. F. Hutchinson, Self-Diffusion in Argon, J. Chem. Phys. 17, No. 11, 1081-86 (1949).

34. E. B. Winn, The Temperature Dependence of the Self-Diffusion Coefficients of Argon, Neon, Nitrogen, Oxygen, Carbon Dioxide and Methane, Phys. Rev. 80, No. 6, 1024- (1950).

35. I. Amdur and T. F. Schatzki, Diffusion Coefficients of the Systems Xe-Xe and A-Xe, J. Chem. Phys. 27, No. 5, 1049-54 (1957).

36. I. Amdur, Low Temperature Transport Properties of Gases. II. Neon, Argon, Krypton, and Xenon, J. Chem. Phys. 16, 190-94 (1948).

37. B. N. Srivastava and K. P. Srivastava, Mutual Diffusion of Pairs of Rare Gases at Different Temperatures, J. Chem. Phys. 30, No. 4, 984-90 (1959).

38. J. Kestin and W. Leidenfrost, An Absolute Determination of the Viscosity of Eleven Gases over a Range of Pressures, Physica 25, 1033-62 (1959).

39. J. Kestin and H. E. Wang, The Viscosity of Five Gases, A Re-evaluation, Trans. ASME 80, 11-17 (1958).

40. G. P. Flynn, R. V. Hanks, N. A. Lemaire, and J. Ross, The Viscosity of Nitrogen, Helium, Neon and Argon from -78.5 to $100^{\circ} \mathrm{C}$ below 200 Atmospheres, Brown University, Metclaf Chem. Lab., Providence, R. I., Tech. Rept. No. BRN-3-P (Nov 1962), NASA N63 11774 .

41. M. Klein, The Determination of Intermolecular Potential Functions from Macroscopic Measurements, to be published. 

U.S. DEPARTMENT OF COMMERCE

WASHINGTON, D.C. 20230

OFFICIAL BUSINESS 